\title{
ESTÉTICAS BASTARDAS DE SUBJETIVIDADES CELEBRIZADAS: SENSUALIZAÇÃO, DEBOCHE E RESISTÊNCIAS NO POP-FUNK DE LIA CLARK
}

\author{
BASTARD AESTHETIC OF CELEBRATED SUBJECTIVITIES: SENSUALIZATION, \\ DEBAUCHERY AND RESISTANCES IN THE POP-FUNK OF LIA CLARK \\ ESTÉTICAS BASTARDAS DE SUBJETIVIDADES CELEBRIZADAS: \\ SENSUALIZACIÓN, BURLA Y RESISTENCIAS EN EL POP-FUNK DE LIA CLARK
}

Rose de Melo Rocha'

Marina Caminha ${ }^{2}$

Resumo: problematizamos neste artigo características da performance midiática da cantora drag Lia Clark, com o objetivo de pensar formas da resistência no âmbito do entretenimento e da cultura pop. A análise de alguns de seus videoclipes é articulada às chaves conceituais da "subjetividade política encorpada" e da "bastardia". Entendemos que há uma centralidade do corpo-mídia travestido e ambivalente de Clark na construção de suas estratégias narrativas, que dialogam fortemente com o humor, a sensualização e o deboche. Este corpo narrativo é também porta-voz de enfrentamentos importantes, que incidem diretamente na luta por audiovisibilidade de gays, mulheres e transexuais.

Palavras-Chave: Cultura pop. Resistência. Lia Clark.

Abstract: the article argues about some characteristics of the media performance of the drag singer Lia Clark, focusing on forms of resistance in the ambit of entertainment and pop culture. The analysis of some of her video clips is articulated to the conceptual

\footnotetext{
Professora do Programa de Pós-Graduação em Comunicação e Práticas do Consumo da Escola Superior de Propaganda e Marketing - ESPM, São Paulo (SP), Brasil. Doutora em Ciências da Comunicação pela Universidade de São Paulo - USP, São Paulo (SP), Brasil. https://orcid.org/0000-0002-7681-5500 E-mail: rlmrocha@uol.com.br

2 Doutora em Comunicação Social pela Universidade Federal Fluminense - UFF, Niterói (RJ), Brasil. Pós-doutoranda no Programa de Pós-Graduação em Comunicação e Práticas do Consumo da Escola Superior de Propaganda e Marketing - ESPM, São Paulo (SP), Brasil. https://orcid.org/0000-0002-9971-6599. E-mail:ninacaminha@gmail.com
} 
keys of "full political subjectivity" and "bastardy." We understand that there is a centrality of the transvestite and ambivalent body-media of Clark in the construction of her narrative strategies, which dialogue strongly with humor, sensuality and debauchery. This narrative body is also a spokesperson for important confrontations, which directly affect the fight for audiovisibility of gays, women and transsexuals.

Keywords: Pop culture. Resistance. Lia Clark.

Resumem: Problematizamos en este artículo características de la performance mediática de la cantante drag Lia Clark, con el objetivo de pensar formas de resistencia en el ámbito del entretenimiento y de la cultura pop. El análisis de algunos de sus videoclips se articula con las claves conceptuales de la "subjetividad política encorpada" y de la "bastardía". Entendemos que hay una centralidad del cuerpo mediático travestido y ambivalente de Clark en la construcción de sus estrategias narrativas, que dialogan fuertemente con el humor, la sensualidad y la burla. Este cuerpo narrativo es también portavoz de enfrentamientos importantes, que inciden directamente en la lucha por la audiovisibilidad de gays, mujeres y transexuales.

Palabras clave: Cultura pop. Resistencia. Lia Clark.

\section{Subjetividade política encorpada: tessituras irreverentes e metamórficas}

Existe alguma resistência (política; subjetiva; estética) possível em contextos de entretenimento pós-massivo? O que pode uma drag, ao transitar da cena das boates e das casas noturnas para a iluminação máxima ativada por uma avalanche de visualizações de videoclipes por ela protagonizados? Que entre-lugar (PRYSTHON, 2003) é este, tecido na dimensão da bastardia (RINCÓN, 2016) e do contrabando de sentidos fazendo ecoar, na batida de um pop-funk irreverente e escrachado, a performance de um corpo caiçara ressignificado, levando o dialeto gay e cabelos à lá Britney Spears para tomadas feitas em praias, bares e galpões abandonados da cidade de Santos, litoral de São Paulo? Lia, Rhael, nomes repletos de atravessamentos pop-pós-periféricos (ROCHA, COSTA e PEREIRA, 2015); eles nos conduzirão nesta escrita.

A drag queen Lia Clark despontou nos cenários brasileiros em janeiro de 2016, através do videoclipe Trava Trava, transmitido pela rede social YouTube e que obteve no início de 2018, quase 4 milhões de visualizações. Lia é encarnada por Rhael Lima de Oliveira, nascido no início dos anos 1990 na cidade de Santos (SP). Rhael afirma ter se caracterizado pela primeira vez como Lia Clark em 2014 para 
se divertir nas boates que frequentava: "Eu decidi [fazer drag] junto com a minha amiga, Lola Lewinsky. No começo, ela me maquiava e saíamos pelas baladas de São Paulo montadas" (GLADIADOR, 2016, p. 5). Em setembro de 2016 a cantora lançou seu Extended Play (EP), contendo sete canções. Além de Trava Trava, dele consta um remix da mesma canção e as músicas Clark Boom, Chifrudo (com a participação da funkeira transexual Mulher Pepita), Baile de Boneca, Boquetáxi e To me curtindo (em parceria com a celebridade drag Pabllo Vittar).

Clark é uma representante muito específica do que vimos chamando (ROCHA, 2018), em consonância às falas nativas, de música-queer, ou, ainda, de drag-artivismo-remix (ROCHA e POSTINGUEL, 2017). Acreditamos que a sua sensualidade escrachada e o seu modo de presença combinatório evocam uma experiência de si - e uma prática comunicativa - de que nos aproximamos analiticamente mediante o conceito de subjetividade política encorpada (ALVARADO; DIÁZ, 2012). A subjetividade de um corpo masculino transformado em uma mulher-mídia, decalcada por adereços e extensões, remete à construção de uma audiovisibilidade em que tensões e brechas se sobrepõem à realidade instituída (seja do corpo, da sexualidade, das exclusões, das cidades, do mainstream fonográfico):

Isto implica que os indivíduos não são apenas reprodutores da realidade e, portanto, sujeitos sujeitados, mas têm a possibilidade da reflexividade, mediante a qual questionam a realidade e, em particular, a vida social em suas diversas expressões. Quando esta deliberação diz respeito à política e, em particular, às instituições que constituem a sociedade, se cria a política como alteridade do político3 (ALVARADO; DÍAZ, 2012, p. 112, tradução nossa).

A argumentação de Alvarado e Díz (2012) está diretamente ancorada em Cornelius Castoriadis e Hannah Arendt, mas também encontra eco em Gilles Deleuze e Félix Guattari. Segundo os autores, a subjetividade assume dimensão política quando a "ação de reflexividade que realiza o sujeito sobre si mesmo e sobre o instituído (...) [centra-se] no plano do público (o que é comum a todos)"4. Além de responder a um foro público, tem seu próprio status, cons-

\footnotetext{
3 Do original: "Esto implica que los individuos no son solo reproductores de la realidad y, por tanto, sujetos sujetados, sino que tienen la po-sibilidad de la reflexividad, mediante la cual cuestionan la rea-lidad y, en particular, la vida social en sus diversas expresiones. Cuando dicha deliberación se hace respecto a la política y, en particular, sobre las instituciones que constituyen la sociedad, se crea la política como alteridad de lo político". 4 Do original: esta será la acción de reflexividad que realiza el sujeto sobre sí mismo y sobre lo instituido, centrándose en el plano de lo público (lo que es común a todos) ".
} 
tituindo, a partir da multiplicidade e de condições históricas mutáveis, tramas compartilhadas (Cf, ALVARADO; DIÁZ, 2012, p. 113).

Dialogando com os aportes metodológicos adotados pelos autores, identificam-se traços específicos da "subjetividade política encorpada" que se aplicam às expressões corpóreo-discursivas de Clark. E isto se dá justamente "quando se entende ao corpo como o espaço no qual se objetivam não apenas as violências, mas as resistências, [e] este pode se reconhecer como meio e fim no processo de constituição do sujeito"s (ALVARADO; DIÁZ, 2012, p. 117; tradução nossa). Por estas vias, o sujeito político é pensado a partir da categoria corpo, considerando nessa abordagem os espaços de configuração e aqueles de exibição dos corpos. Temos assim, importantes pistas para analisar os videoclipes de Lia, não apenas como expressividade artística, mas também como parte de um texto autobiográfico, publicizado e autorreflexivo, dotado de intencionalidade de fala e diretamente dirigido a um foro público (midiatizado).

O corpo político de Lia Clark - tecido nos entremeios da visualidade trans e da audiovisibilidade drag - poderá então ser nomeado como lócus de subjetivação que dota de sentido um território biossimbólico dissidente/insurgente, ambíguo e ambivalente. Nesta direção, adotamos em nosso artigo a concepção porosa de reexistência, menção explícita à capacidade (subjetiva) de se reinventar, mas o que nos é caro, as formas outras de fazer política, de se pensar o político e de se reapresentar politicamente, em especial em expressões resilientes e esteticamente informadas.

A própria compreensão de experiência estética se poliniza e se desdobra nas subjetividades políticas insurgentes que emergem do performar a um só tempo autobiográfico e encenado de Clark. Lia é Rhael. Rhael é Lia. Ambos se confundem e se mimetizam com e na obra estética, por assim dizer. A subjetividade (política) de Rhael pressupõe a externalidade (estético-comunicacional) de Lia. Corpo bios e corpo mídia, indissociáveis. Clark não é, insistimos, um em si. Obra aberta, corpo metafórico e metamórfico, demanda e implica a imaginação do vidente que é chamado a decifrar ou completar as brechas de sua fala, assim como prevê, tal como narrado em um clipe, a surpresa de alguns de seus parceiros ao se revelar o falo da drag.

Marcondes Filho (2017), em artigo recente, discute hipóteses de Deleuze e Guattari que irão auxiliá-lo em investida particular: compreender a comunicação como evento estético. A respeito dos devires não humanos que não só habitam como constituem subjetividades humanas, Marcondes Filho atenta-se à seguinte

5 Do original: "cuando se entiende al cuerpo como el espacio en el que se objetivan no solo las violencias, sino las resistencias, este se puede reconocer como medio y fin en el proceso de constitución del sujeto". 
argumentação de Guattari: “A subjetividade (...) [é também] fabricada nas grandes máquinas sociais, massamediáticas, linguísticas, que não podem ser qualificadas de humanas" (GUATTARI, 1992, p. 20 citado por MARCONDES FILHO, 2017, p. 6). Aceitando que "há 'máquinas de subjetivação' em toda parte" (MARCONDES FILHO, 2017, p. 6), Marcondes Filho incomoda-se com a paralisia tácita que resultaria de tal ordem totalizante, esta que, segundo afirma, seria incapaz de considerar "as ações consequentes de agentes humanos capazes de detonar movimentos, mudanças, inversões de rotas" (MARCONDES FILHO, 2017, p.6).

"Os seres humanos são o que fazem com seu corpo", dizem Alvarado e Díaz (2012, p. 117) e, nesse aspecto, "os corpos adquirem uma importância central em sua potencialidade de abrigar tanto operações de dominação como práticas de desobediência" (2012, p. 117). Justamente aí se localizam linhas de fuga a partir e com os corpos, e, mais ainda, que se poderia atribuir aos corpos em suas múltiplas potencialidades a agência política de transformação - dos selfs que os abrigam e da sociedade em que se inserem como actantes. De ordem combinatória e bastarda a subjetividade política encorpada de Lia Clark transita pela cena midiática ancorada em uma miríade de narrativas que, tradicionalmente, seria possível associar a forças de assujeitamento. Contudo, como propomos neste artigo, a ironia e o exagero são ferramentas de inversão mobilizadas pela drag; há um jogo constante de parece, mas não é habilmente acionado, o que não nos permite afirmar a expropriação da autonomia subjetiva ou a mera promoção de discursos estandardizados.

A presença pública e as produções audiovisuais protagonizadas por Clark moldam-se por inúmeras referências ao universo do entretenimento, em expressões variadas e bastante díspares. Corpo-mídia atravessado por narrativas midiáticas e "pop-líticas" (RINCÓN, 2016), transitando das séries norte-americanas ao dialeto gay publicizado, Lia, criatura de seu criador, Rhael, se dá a ouvir/ver: é uma artesania de si que recusa e ironiza qualquer pretensão à verdade, a um vir a ser fundado em valores profundos, últimos, preservados, ocultos. Furacão da pele e da máscara, da maquiagem e do rebolado, a processualidade é, em si, o modo de existência apresentado. Não sou exatamente o que você está pensando, sugere Lia, rindo da surpresa que causará na hora do trava-trava. No truque está sua vontade de poder.

\section{Pop-funk de matrizes bastardas}

Os videoclipes de Clark conformam, antes de tudo, uma imagem pop, atravessada por diferentes estilos inscritos nas matrizes populares e massivas; tam- 
bém pressupõem, em seus contextos de produção, disseminação e recepção, a tecnoinformacionalidade pós-massiva. Seu nome é uma alusão a duas personagens televisivas: Lia Khey, participante do Big Brother Brasil 10, na Rede Globo, em 2010, e Naomi Clark, da série americana 90210, da The CW, em 2008. Lia Khey ficou conhecida no reality show através de suas performances moldadas pelo que se pode associar a uma expressividade popular: protagonizou brigas marcadas pelos excessos do corpo, com gritos altos, choros explosivos, caras e bocas acentuadas. Já a personagem Naomi Clark, era representada como uma das alunas mais populares e desejadas do colégio, referenciando um tipo de jovem desejada aos olhos de todos, que encarnava de modo estereotípico a mulher média ideal, ancorada no imaginário dos vencedores, dos bem-sucedidos. Afinal, a série contava as experiências de jovens americanos em um plano muito específico: o universo luxuoso de Beverly Hills (SOUZA, 2017).

No jogo entre extremos como este, Clark é, ainda, o corpo masculino-feminino/feminino-masculino. Da ambivalência descomedimento/perfeição modelar, emerge a ambiguidade constitutiva de seu modo específico de ser drag, constantemente explorado nas letras e imagens das músicas. Como nos lembra a patricinha de longos cabelos louros e figurino sintético cor-de-rosa, que trai o marido (que a traía), o chifrudo do videoclipe de mesmo nome, ela sabe que é gostosa, e, mais ainda, sabe que "eles gostam é da piroca", escrachado desvelamento de práticas trans e homossexuais capitaneadas por homens que, ao que sugere Lia, escondem suas preferências e escolhas.

Uma ordem de comunicação tensiva, que não permite leituras dicotomizantes, emerge desta fala drag audiovisibilizada. Lia, afrontando até mesmo restrições de setores específicos do universo Lésbicas, Gays, Bissexuais, Travestis, Transexuais, Transgêneros, Intersex e Queers (LGBTIQ), joga e ironiza com sua visualidade desejante as condições de possibilidade de exercer sua sexualidade ambivalentemente travestida. Lia, santista, retoma, talvez involuntariamente, uma linhagem do pop nacional dos anos 1990, em que cantores como Fausto Fawcet enalteciam figuras do submundo carioca, jogando luz e extraindo musicalidade de personagens desviantes e fortemente sexualizados.

Através do diálogo entre essas referências, percebemos um ponto de partida para entendermos os formatos e conteúdos que a compõem, tanto no que se refere a sua montagem como drag queen, quanto na linguagem em mosaico, na narrativa pop-folhetinesca que caracteriza as produções audiovisuais da ar-

6 Trecho da música "Chifrudo", de Lia Clark. 
tista. É um jogo de inversões que se faz entre elementos do grotesco (através das citações cotidianas e populares para órgãos do corpo humano, tais como caralho e cu), as performances que descrevem o sexo, as imagens em close de sua bunda rebolando para a câmera, por exemplo, e as referências a representações de mulher advindas de uma estética espetacularizada, de higienização do popular, que pode ser percebida na estilização de jovens americanas modelares no cinema e em algumas séries, tais como a citada personagem Naomi Clark.

Assim, a poética audiovisual de Lia Clark será compreendida como uma projeção de "culturas bastardas", que, nas palavras de Omar Rincón (2016, p. 31), são "degeneradas herdeiras das boas culturas cultas (Ilustração), as tradições densas (Identidade), o folclórico (povo), o midiático (entretenimento e espetáculo), o conectivo (internet e celular)", marcadas por diferentes afiliações - vários pais, mas apenas uma mãe: o local, espaço de ressignificação das estéticas migrantes, que nos chegam por diferentes cantos do mundo e formulam ambientes por meio dos quais o pop se configura como elemento de diversão e prazer nas cenas midiáticas:

Culturas bastardas porque renunciam às referências autênticas e densas para ganhar as instabilidades do fluxo: essas made in USA. Essas que se nomeiam em inglês, mas que acenam para o abya-yala do ancestral bom viver; essas que assumem que somos praticantes de muitos modos do popular (RINCÓN, 2016, p. 34).

Nesses muitos modos de praticar o popular, o deboche aparece como marca cênica central para as inspirações estéticas vinculadas às diferentes filiações performadas por Lia Clark. A própria cantora entende que através do riso pode se aproximar do público com mais facilidade, negociar espaços do dizer e se fazer ver. Segundo afirma, "[a] principal ideia é fazer as pessoas se divertirem, seja com música, vídeos, posts, fotos. E eu me divirto muito sendo a Lia também" (CLARK, 2016, p. 2). Fazer divertir, divertindo-se com este modo de produzir cultura é igualmente uma estratégia de subjetivação.

$\mathrm{Na}$ trilha desse prazer, ela povoa videoclipes com seus rebolados, caras e bocas, discutindo o seu sexo, seus desejos e suas aspirações. O deboche se constitui pela inversão das imagens que configuram Lia Clark, nas transições entre o popular e o glamoroso, entre o luxo e o lixo, nas palavras coloquiais que destronam nas explicações sobre sexo os termos inscritos nos dicionários da língua portuguesa pelo falar do universo de LGBTIQ - é o prazer forjado no corpo e para o corpo: 
[...] Boa noite, eu gostaria de pedir um táxi, mas vem com tudo, hein! $\mathrm{O}$ meu nome é Lia Clark e aqui não tem frescurinha. Tô mandando o papo nele, falei várias baboseiras, ele vai cair na minha, ai mas de qualquer maneira. Tá cheio de gracinha, tá todo risonho. O boquetáxi rola hoje, hein? Seria meu sonho? Bota o menino pra jogo, aumenta a quilometragem, vou pagar essa corrida, com a minha sacanagem. Garanti essa carona. Já vou dá aquele migué, depois do boquetáxi nunca mais andei a pé.?

A palavra boquetáxi é um neologismo que faz alusão ao sexo oral realizado em um homem, no linguajar corriqueiro, boquete. A junção com a palavra táxi refere-se à possibilidade de paquerar e se relacionar com o motorista, realizar o prazer e, com isso, ter ainda a chance de não pagar a corrida. A letra encena uma tática, arte de tirar proveito das situações, usada pela personagem encarnada no videoclipe para fazer do seu prazer uma solução para não andar a pé em um dia de caos na cidade. Esse é um exemplo que pontua o que chamamos de deboche em Lia, uma transição entre imagens que se confrontam: do luxo ao lixo, do lixo ao luxo (CERTEAU, 2005).

Em cena de Trava Trava, a cantora aparece em uma janela grafitada, olhando diretamente para a câmera. Enquanto canta, vemos uma frase pichada no rodapé da janela: "E você? Crê que sua heterossexualidade tem cura?". Essa inscrição faz referência ao projeto de lei (PDC 234/11) ${ }^{8}$ conhecido popularmente como cura gay, apresentado à Câmara dos Deputados por João Campos (PSDB-GO). A proposta tinha como intenção elaborar diretrizes para as formas de atuação dos psicólogos em relação a orientação sexual, centralizadas nos homossexuais (RAMOS, 2013).

O projeto foi tramitado e aprovado no dia 18 de junho de 2013 pela Comissão de Direitos Humanos e Minorias da Câmara, à época presidida pelo pastor evangélico Marco Feliciano (PSC-SP). Esse processo gerou uma reação contrária de parte da população brasileira, disputada midiaticamente e nas ruas das cidades, com apoio do Conselho Nacional de Psicologia. Diante da reação nacional, a direção do Partido Social Democrata Brasileiro (PSDB) se colocou contrária à proposta, o autor do processo pediu pela retenção do seu requerimento e em 2 de julho de 2013 o projeto foi arquivado (RAMOS, 2013).

\footnotetext{
7 Transcrição de trecho de CLARK, Lia. LIMA, Pedro. Boquetáxi. [Direção e Edição: Gabriel Riccieri Roteiro e Codireção: Lia Clark Produção Musical: Pedrowl, Lia Clark. Realização: Lia Clark Produções]. (C) 2017 Lia Clark Records. $3 \mathrm{~m} 58$.

8 Projeto de Decreto Legislativo arquivado, pretendia sustar resolução do Conselho Federal de Psicologia, que estabelecia normas de atuação para os psicólogos em relação à questão da orientação sexual.
} 
Quando Lia Clark utiliza a frase, deslocando a palavra homossexualidade para heterossexualidade, torna visíveis as marginalizações contidas em um discurso homo/transfóbico que chegou a se materializar em um projeto de lei, votado e aprovado no Congresso Nacional. Tais inversões e a ironia convivem com a exaltação de uma vida glamorosa e de matiz celebrizada. A subjetividade política encorpada de Lia, midiatizada em seus videoclipes, não é unívoca ou livre de contradições. A identificamos como entertainer do entre: entre referências e ausências, entre o que exclui, marginaliza e o que celebrifica, entre o entretenimento e a produção de um lugar para existir.

A construção imagética de Lia Clark emergiu como ocupação midiática botton-up: ainda que não tenha sido convidada a entrar pela porta da frente no mainstream televisivo ou fonográfico, jogou com as possibilidades de descompressão tecnológica e com as ferramentas expressivas advindas de narrativas da própria indústria do entretenimento. Sua feminilidade/travestilidade exagerada sincroniza a marginalidade e o espetáculo. Através de suas canções e de sua performance audiovisual, marcadas por pinceladas cômicas e pelo deboche (de si mesma, do mundo das representações, dos papéis sociais conservadores), a cantora torna-se um fenômeno de escutas e compartilhamentos.

\section{Reexistências, com vontade}

No início do videoclipe Trava Trava, Lia Clark se apresenta ao público, dizendo: "Não tenho dó, nem piedade. O Trava Trava é com vontade". Enquanto ouvimos essas palavras, assistimos cenas do corpo dançante da artista em três diferentes lugares. O primeiro é um espaço interno coberto de pichações e grafites na parede central, o chão de cimento sem revestimento, no canto esquerdo uma moto branca, um conjunto de cadeiras de plástico empilhadas, panelas e um sintomático extintor de incêndio; no centro, uma mesa construída de tijolos também grafitados e pedaços de madeira; à direita, uma parede na cor verde e duas janelas ainda não finalizadas de onde se vê um corredor com paredes também grafitadas.

Esse lugar projeta a ideia de uma casa/rua, ou de um interior abandonado, com quase nenhuma mobília, um local de descarte. Estão ali apenas entulhos envelhecidos e materiais de construção, constituindo uma estética da precariedade e do inacabamento como elemento cênico. A segunda imagem é de uma

9 Transcrição de trecho da música Trava trava, de Lia Clark. 
praia, onde visualizamos o mar, alguns barcos de pesca, poucos banhistas e a cantora vestida em um biquíni duas peças florido.

Nas cenas, Clark aparece dançando, olhos e boca exageradamente maquiados. Seu corpo em movimentos sincopados ocupa o centro das tomadas. Ela olha diretamente para a câmera, recurso narrativo que pressupõe um espectador que se deseja seja implicado tanto na provocação ou na conclamação existencial da artista: "Me encarar nessa parada. Tem que ter dignidade. É isso mesmo, hein!”’o. Ela convida, desafia, sensualiza. Na primeira cena descrita há uma frase grafada em uma das paredes, a conhecida afirmação "meu corpo minhas regras", palavra de ordem entoada/ cantada nas Marchas das Vadias do Brasil", e que se popularizou fortemente em diversas evocações feministas contemporâneas. Esta citação em conjunto com os rebolados da artista, apropriando-se dos cenários filmados, são pistas para perguntas como: "Quem é Lia Clark?”; “O que ela que dizer?, ou melhor, "O que ela quer ser?.

Lia transita com desenvoltura por este real encenado ou reapresentado nos videoclipes. Sempre sorrindo, seus grandes olhos pintados e arregalados nos remetem à obra em nanquim de Paul Klee, Angelus Novus, utilizada por Walter Benjamin em seu ensaio Sobre o conceito de história ${ }^{12}$ para descrever a destruição criadora característica da modernidade, resultando em uma situação inexorável de limiaridade entre o passado (a morada das ruínas) e o futuro (a casa do incerto porvir). Anjo de uma outra história, mas igualmente corpo-reapresentação limítrofe, Clark parece usar os cenários como extensão de seu corpo, tornando visível para o público o modo como ela deseja ser (re)conhecida. Há uma interconexão entre duas visualidades: um corpo fílmico, e um self narrativo, que dá voz e visibilidade ao próprio corpo da drag-cantora. Ambos, por sua vez, são metafórica e metonimicamente extensão de Rhael, corpo por trás da persona Lia Clark, esta que dá voz e imagem à subjetivação de seu criador.

Amaral, Barbosa e Polivanov (2015) discutindo perspectivas de resistência de subculturas juvenis em contextos digitais, propõe distinguir a apresentação (termo "mais adequado para se pensar as construções de identidade dos atores sociais no ciberespaço" (2015, p. 3), da representação ("designação ou delegação que se dá a algo ou alguém para fazer às vezes de um objeto/sujeito em seu

\footnotetext{
10 Transcrição de trecho da música Trava trava, de Lia Clark.

"Edição nacional da SlutWalk, movimento que surgiu a partir de um protesto realizado em 2011 em Toronto (Canadá), após a denúncia de uma série de agressões e violências sexuais cometidas contra mulheres na Universidade de Toronto, e após a declaração do policial Michael Sanguinetti, sugerindo que as mulheres não se vestissem como vadias, de modo a evitar os abusos.

12 BENJAMIN, Walter. Sobre conceito de história. In: Walter Benjamin. Obras escolhidas (Magia e técnica, arte e política. São Paulo: Brasiliense, 1994, p.222-232.
} 
lugar, reproduzindo-o" (2015, p. 3) e ambas da re(a)presentação, conceito que as autoras acertadamente associam à ideia de ressignificação, atualização ou renovação (de uma expressão cultural ou subjetiva já existente) (Cf. AMARAL; BARBOSA; POLIVANOV, 2015, p. 3). Ainda que não estejamos analisando exclusivamente a performance de Lia nas redes digitais, a chave da reapresentação é fundamental para a análise de sua audiovisibilidade, em termos das estratégias estético-artísticas adotadas e na perspectiva mesma de sua experiência de subjetivação, ancorada em terrenos a um só tempo reais e encenados.

Em nosso caso específico de estudo, observamos que é a partir do corpo-biomidiático da artista que se dão as reapresentações, materializadas em uma série de inversões e trânsitos, uma vez que, "[c]om o corpo se pode simular, fazer imposturas, fazê-lo máscara que oculta e também permite ser outros no mesmo corpo." (ALVARADO; DÍAS, 2012, p. 121). O corpo montado é expressão (de si) e convite à reinvenção (de outros corpos, olhares, escutas, visões de mundo, práticas cotidianas). A montação de Lia, efetivo exercício de autoconstituição, "é a vontade expressa de um ser que opta por mudar não a partir de forças externas, mas como desdobramento da própria intencionalidade" (ALVARADO; DÍAS, 2012, p. 122).

Em outra sequência do videoclipe Trava Trava há uma mudança no tom narrativo. A cantora aparece em um cenário todo branco, usando botas pretas até o joelho, um maiô também na cor preta, em contraste ao excesso de cores e referências estéticas que compõem as outras cenas. Há apenas um homem atuando, de calça preta, sem camisa, com um gorro cobrindo a cabeça, e que se apresenta como objeto dos desejos de Lia; ela faz um movimento com as mãos (como se estivesse empurrando o ator) para que ele fique aos seus pés, deitado no chão.

Sobre o corpo desse homem, faz movimentos que imitam uma cena de sexo na qual o comando é detido pela artista. Nessa passagem, Lia encarna uma muIher poderosa, uma dominatrix, aludindo ainda ao universo imagético-temático de cantoras pop como Madonna, Lady Gaga e Beyoncé. Posteriormente, o videoclipe segue mesclando as imagens desses três cenários como importantes elementos que dramatizam as reapresentações do corpo de Clark.

\section{Considerações finais: o pop e a resistência}

De que modo Lia Clark dialoga com o universo das divas pop? Entendemos que o status de celebridade e diva auferido por algumas cantoras pop contemporâneas pode ser pensado como parte da configuração de imaginações diaspóricas, marcadas pelas migrações (relações entre o global e local) e comunicações 
tecnológicas (relações entre virtual e presencial). Elas promoveriam um deslocamento do ritual e das criações mitológicas para os espaços do entretenimento e os circuitos de celebrização, configurando aquilo que Arjun Appadurai (2005) nomeia como novas mitografias:

\footnotetext{
Estas diásporas trazem a força da imaginação, como memória e como desejo, para as vidas de muita gente vulgar, para mitografias diferentes das disciplinas do mito e do ritual de tipo clássico. O cerne desta diferença é que essas novas mitografias são atestados de novos projetos sociais e não apenas contraponto das certezas da vida cotidiana (APPADURAI, 2005, p. 17).
}

Quando Lia Clark se apresenta um feminino peculiar também se constitui. Ele se funda no travestismo e negocia com a transexualidade, dialogando, ainda, com a ideia de uma afetação/afeminação homossexual fortemente positivada. A mitografia da bandiva, neologismo que aqui utilizamos para descrever a fusão diva/bandida (na direção de mulher perigosa, sedutora, que sabe o que quer e é protagonista de suas ações), está situada em um entre-lugar ambivalente e descomedido. Nele, o disfarce é a face. Vamos vê-la sair em defesa das traídas, em Chifrudo, encarnando melodramaticamente a dor e a revanche de mulheres (transexuais, travestis e travestidas) que, na verdade, não se deixariam iludir.

Em clara remissão à princesinha do pop Britney Spears (que Clark declarou ser sua artista favorita), inicia o videoclipe vestida de rosa, figurino comportado de colegial norte-americana, uma tiara em forma de coroa na cabeça. Na acentuação maliciosa de certa maneira caricata de representação modelar da mulher, a drag une e ressignifica traços mainstream e pornográficos originalmente voltados à objetualização e regulação do exercício da sexualidade feminina. Mas a patricinha loura, dedicada ao marido, em uma sensualidade adolescente, que ocupa as cenas iniciais do videoclipe encerra sua atuação vestida em um macacão colado ao corpo, cujos recortes a revelam e desnudam, e entoa singela: "pau no cu do mundo..."13.

Lia não pretende viver na invisibilidade. Em seu devir drag, e, em sincronicidade, em seu devir gay, Clark faz uso do seu corpo desejante como uma pulsão que atravessa e é atravessada pelos circuitos da espetacularização e dos consumos midiáticos. Nesta negociação ela pode ser, possuir uma renda e se fazer ouvir - uma disputa que se constitui pela conscientização/provocação da existência/ permanência de alteridades audiovisíveis. Não por acaso, a força-mulher proje-

13 Trecho da música Chifrudo, de Lia Clark. 
tada por e através de Lia Clark é constituída pela relação entre as imagens que localizam a cantora no espaço da travestilidade e do universo gay, passam pelos interiores (inacabados/abandonados/ocupados) e pela praia, em conjunto com espelhamentos de grandes personalidades do universo musical e feminino do pop.

É a partir deste tensionamento que essa mulher drag, que não tem "frescurinha", como diz em um refrão de Boquetáxi, passeia, rebola, quica e reafirma sua dignidade através de uma debochada hipererotização. Tais projeções são maneiras de narrar que dialogam com um ethos do capitalismo contemporâneo (midiático, tecnicista), não apenas por que faz uso da mídia e nela deseja permanecer. Clark negocia e se apropria de determinadas expressões de divas do pop associadas a representações muito específicas sobre a mulher (sedutoras, erotizadas, dotadas de voz e donas de sua imagem, inclusive em termos mercadológicos).

Elas são referências importantes de legitimação desse corpo insurgente, que, em certo sentido, reafirma a norma, para melhor transgredi-la. Compreendemos as ambivalências que modelam a artista. Porém, quando propomos analisar a construção do feminino através da imagética de Lia Clark enfatizamos outras leituras possíveis desta ocupação midiática que contemplem suas pluralidades expressivas.

Apesar do espelhamento em símbolos sexuais extremamente convencionais e amplamente respaldados pela mídia (caso das chamadas mulheres-fruta, que Clark assume como referência), a apropriação não se dá aos moldes de um pacote fechado, mas sempre como texto estético-discursivo a ser explorado, recombinado, rearranjado. É o que se nota em Trava Trava, com a presença da expressão grafada na parede: meu corpo minhas regras, que alude diretamente a um imaginário alinhado ao discurso feminista contemporâneo, chamando a atenção do público para uma sobreposição: a atuação de mulheres para a ocupação de diferentes espaços sociais e a presença da drag, mulher/homem travestida, assumindo essa mesma posição de sujeito. Através das ambivalências contidas no audiovisual uma disputa pelo dizer está inscrita na narrativa. De um lado, a aceitação do devir drag como um ser mulher combinatório, que joga com os artifícios e com a transitoriedade, de outro, um projeto respaldado pela liberdade de corpos femininos e masculinos escolherem, autonomamente, seus modos de ser, suas regras de conduta, a vivência de sua sexualidade e, inclusive, as transições de gênero.

Por esses motivos, pode-se entender sua trajetória audiovisibilizada como prática de reexistência, um modo de estar no mundo (inclusive no mundo do entretenimento) marcado pela reinvenção e ressignificação, chegando mesmo ao enfrentamento das exclusões e segregações. O conceito de reexistência nos chega através da dissertação de mestrado sobre o hip hop, de Jacimar Silva 
Gomes (2009, p. 117). A autora entende que as práticas que formulam a cultura hip hop se constituem através da "dialética entre assimilação e resistência" por que são indissociáveis do consumo e dos circuitos midiáticos.

Segundo Gomes (2009), a mídia é um lugar importante pelo alcance e visibilidade, tornando-se um eixo mediador entre o hip hop e as juventudes. Deste modo, o consumo pressuporia uma morada para a reinvenção do existir através da formulação de outros estilos de vida. Dialogado com esta perspectiva analítica, percebemos que o pop-funk de Lia, em sua construção estética bastarda, se constitui na afirmação de vozes e corpos insurgentes, mergulhados no caldo cultural da música pop e das diásporas narrativas da alteridade. Dançar, rebolar, sambar na cara, expressões tradicionalmente dissociadas do fazer político, assumem em Lia, conquanto mediadora social, a função estratégica de afirmação de um lugar de fala constantemente denegado, ridicularizado, oprimido. Assim,

[a] prática da cidadania, via ações comunicativas que passam pelo entretenimento e pelo engajamento social, mesmo que não seja exercida em sua plenitude, possibilita a construção de novas formas de modificação das estruturas sociais, políticas e econômicas numa sociedade em que a exclusão social e a pobreza são fatores alarmantes (GOMES, 2009, p. 82).

Elemento importante na construção de redes simbólicas de afetividade e reconhecimento, as manifestações de receptores nas redes sociais da cantora reiteram a concatenação entre narrativa audiovisual, identificação e respaldo social. Portanto, concordamos com Gomes quando propõe uma ressignificação da resistência através do reexistir:

\footnotetext{
Os vários tipos de mídia e as novas tecnologias devem ser vistos como uma das mais significativas forças em busca de mais respeito para a diversidade cultural, mas é engano creditar aos meios de comunicação a total responsabilidade pela construção da identidade, pois seu papel principal é a mediação do sujeito com o seu ethos. Por mais relevante que seja a influência da mídia nesta relação, a subjetividade é humana, e social, é ela que está por trás das nossas escolhas mais definidoras (GOMES, 2009, p. 15).
}

Gostaríamos finalmente de propor um alargamento da categoria reexistência para nos aproximar dos usos que Clark faz do corpo, como instância de entendimento de si e como maneira de afetação de outrem. Para tal, recorremos 
ao conceito de biopotência, tal como proferido por Peter Pál Pelbart (2003). Segundo o autor, o capitalismo contemporâneo opera no gerenciamento das subjetividades, projeta forças através da colonização da imaginação, resultando na noção da vida como capital, ou seja:

[i]ncide sobre nossas maneiras de perceber, de sentir, de amar, de pensar, até mesmo de criar. Se antes ainda imaginávamos ter espaços preservados da ingerência direta dos poderes (o corpo, o inconsciente, a subjetividade), e tínhamos a ilusão de preservar em relação a eles alguma autonomia, hoje nossa vida parece integralmente subsumida a tais mecanismos de modulação da existência (PELBART, 2008b, p. 1).

Desse modo, continua ele, é um contexto de dominação em que as ferramentas através das quais os poderes são exercidos tornaram-se mais fluídas, espraiadas, inominadas e moleculares e, por esse motivo, há dificuldades em encontrar espaços de resistências. O corpo e a subjetividade aparecem como esferas centrais de ingerência mercantil, escrutinados pelas espetacularizações e tecnoprojeções que operam na modelação de um corpo capital, assujeitado e anestesiado.

Pelbart (2008b) nomeia essa assepsia, disfarçada de investimento/produção da vida, de niilismo biopolítico, um agenciamento que não está mais circunscrito aos totalitarismos, é parte constituinte dos regimes democráticos do ocidente, através da centralidade do consumismo, da prescrição do prazer e da felicidade, de uma existência medicalizada que restringe a subjetividade ao corpo:

Por um lado, trata-se de adequar o corpo às normas científicas da saúde, longevidade, equilíbrio, por outro, trata-se de adequar o corpo às normas da cultura do espetáculo, conforme o modelo de celebridades (PELBART, 2008b, p. 5).

Se o capitalismo contemporâneo é uma experiência que reveste, esquadrinha e amortece o nosso corpo, podemos dizer que é uma forma-vida, mas não a única. É através da coexistência e tensão entre a captura da vida pelo capital e a própria vida que Pelbart recupera a noção de resistência como linha de fuga, trajetórias de saída que perfuram a anestesia e permitem o encontro com outras formas-vida:

Ora, como não pensar que há outros sentimentos de si imagináveis, ou mesmo impensáveis, em estado embrionário, em gestações complexas no entrocamento entre o homem, as máquinas, os fluxos materiais 
e imateriais, recriando a subjetividade imanentemente, em todas as suas manifestações? (PELBART, 2000, p. 18).

A noção de biopotência se constitui no entrelaçamento entre corpo, subjetividade e afetividade. Retomando o conceito de ética, proposto por Spinoza (2008), Pelbart vai dizer que o indivíduo é constituído pelos diferentes atravessamentos afetivos. Os sentimentos são inscritos nos encontros que produzimos, como forças de movência, que podem aumentar ou diminuir a nossa potência de ação. Nesse sentido, com que forças podemos fazer surgir uma contrapartida que possa humanizar a vida em suas diferentes maneiras de afetação?

É através das disputas entre a subjetivação capitalista e outras subjetividades que a biopotência incide sobre o corpo para que as prescrições sobre "amor, felicidade, vida e beleza" possam ser questionadas, provocadas e quem sabe fomentar outras condições de existência (Cf. SZPACENKOPF, 2017). Assim, diz o autor:

Estar à altura do que nos acontece é a única ética possível, estar à altura dos acontecimentos que se esteja em condições de propiciar nas mais diversas escalas, moleculares e molares, recusando o niilismo biopolítico e suas formas cada vez mais insidiosas e capilares. A esses dispositivos vários, dos quais um certo teatro faz parte, eu chamaria de dispositivos biopolíticos, onde está em jogo uma potência de vida, uma biopotência (PELBART, 2008a, p. 37).

Afirmamos, portanto, a reexistência como um estar no mundo que pressupõe um tramar narrativo não essencialista, que se abre a projetos de novas possibilidades do sentir. É uma circulação que se configura no encontro dos corpos, como esferas de afetação que nos motivam para a ação, humanização e contágio. Implica coexistir e negociar com os dissabores de uma vida capital, perfurando as armaduras que nos são impostas sem que tenhamos escolhido viver sob elas. $O$ espaço midiático pós-massivo constituído por Lia Clark através das brechas inscritas nas tecnicidades e na mobilização do corpo é potência afetiva em movimento. Esta morada possível projeta um deslocar de sensações que se designa a outros corpos. De um lado, a tentativa de se fazer visível para quem marginaliza, de outro, uma possibilidade de ancoragem para os que se encontram em condição similar. 


\section{Referências}

ALVARADO, Sara Victoria; DÍAZ, Álvaro. Subjetividade política encorpada. Revista Colombiana de Educación, v. XX, n. 63, p. 111-128, 2012. https://doi. org/10.17227/01203916.1689

AMARAL, Adriana; BARBOSA, Camila; POLIVANOV, Beatriz. Subculturas, re(a)presentação e autoironia em sites de rede social: o caso da fanpage "Gótica Desanimada" no Facebook. Revista Lumina, v. 9, n. 2, p. 1-18, dez. 2015.

APPADURAI, Arjun. Dimensões culturais da globalização. Lisboa: Teorema, 2005.

CERTEAU. Michel de. A invenção do cotidiano: artes de fazer. Petrópolis, RJ: Vozes, 2005.

CLARK, Lia. Conheça Lia Clark, Drag queen funkeira que superou Metralhadora e Baile de favela nas paradas. Entrevista a Felipe Gladiador. Site R7. São Paulo, 22 fev. 2016. Disponível em: http://entretenimento.r7.com/pop/fotos/conheca-lia-clark-Drag-queen-funkeira-que-superou-metralhadora-e-baile-de-favela-nas-paradas-22022016\#!/ foto/2. Acesso em: 10 ago. 2017.

CLARK, Lia. Trava Trava. Youtube. Direção e Edição: Gabriel Riccieri Produção Musical: Pedrowl, Lia Clark, Vitor Martins. Realização: Lia Clark Produções (c) 2016 Lia Clark Records. 3m24. Disponível em: https://www.youtube.com/watch?v=KgUGMDHU7d8. Acesso em: 3 jun. 2017. 03/06/2017.

CLARK, Lia. Chifrudo. Youtube. Direção e Edição: Gabriel Riccieri. Produção Musical: Pedrowl, Lia Clark Realização: Lia Clark Produções (c) 2016 Lia Clark Records.4m22. Disponível em: https://www.youtube.com/watch?v=0JK97kvgAok. Acesso em 3 jun 2017.

GOMES, Jacimar Silva. Paixão em estado bruto. Movimento Hip Hop: Palco e Projeto de uma juventude. 2009. 205f. Dissertação (Mestrado em Comunicação Social) - Programa de Pós-graduação em Comunicação Social, UFF, Niterói, 2009.

KELNNER, Douglas. A cultura da mídia. São Paulo: Edusc, 2001.

MARCONDES FILHO, Ciro. Elemento para a construção de uma comunicologia. De como melhor compreender a comunicação considerando-a como um evento estético. XXVI Encontro Anual da Compós, 2017. Anais... São Paulo: Cásper Líbero, 2017.

PELBART, Peter Pál. A vertigem por um fio. São Paulo: lluminuras, 2000.

PELBART, Peter Pál. Vida Capital: Ensaios de biopolítica. São Paulo: Iluminuras, 2003.

PELBART, Peter Pál. Elementos para uma cartografia da grupalidade. In: SAADI, F. e GARCIA, Silvana (org.). Próximo Ato: Questões da Teatralidade Contemporânea. São Paulo: Itaú, 2008a. 
PELBART, Peter Pál. Vida e morte em contexto de dominação biopolítica. Instituto de Estudos avançados da USP (IEA). São Paulo, 3/10/2008. 2008b. Disponível em: http:// www.iea.usp.br/publicacoes/textos/pelbartdominacaobiopolitica.pdf/at download/ file. Acesso em: 26 fev. 2019.

PRYSTHON, Ângela. Margens do mundo: a periferia nas teorias do contemporâneo. Revista FAMECOS, Porto Alegre, n. 21, p.43-50, ago. 2003. https://doi.org/10.15448/19803729.2003 .21 .3212

RAMOS, Bruna. Entenda o projeto de "cura gay". Site EBC. Brasília, 19 de julho 2013. Disponível em: http://www.ebc.com.br/cidadania/2013/06/entenda-o-projeto-de-cura-gay. Acesso em: 9 jun. 2017.

RINCÓN, Omar. O popular na comunicação: culturas bastardas + cidadanias celebrities. Revista Eco Pós, v. 19, n. 3, p. 27-49, 2016.

ROCHA, Rose de Melo; SILVA, Josimey Costa da; PEREIRA, Simone Luci. Imaginários de uma outra diáspora: consumo, urbanidade e acontecimentos pós-periféricos. Galáxia, São Paulo, n. 30, p. 99-111, 2015. Disponível em: https://revistas.pucsp.br/index.php/ galaxia/article/view/20453/18256 Acesso em: 26 fev. 2019. https://doi.org/10.1590/198225542015220453

SOUZA, Nauan. Lia Clark em entrevista para o 'Sério, Nauan?': "Quero muito ter a oportunidade de fazer um feat com o Bonde das Maravilhas e a Candy Mel". Site Sério, Nauan? 1 de fev. 2017. Disponível em: http://serionauan.com/2017/02/01/lia-clark-em-entrevista-para-o-serio-nauan-quero-muito-ter-a-oportunidade-de-fazer-um-feat-com-o-bonde-das-maravilhas-e-a-candy-mel/. Acesso em: 9 jun. 2017.

SPINOZA, Benedictus. Ética/Spinoza. Belo Horizonte: Autêntica, 2008.

SZPACENKOPF, Marta. Entrevista com Peter Pál Pelbart: Nossa sociedade está esgotada de tudo. $O$ Globo. Rio de Janeiro, 20 de abril 2017. Disponível em: https://oglobo.globo. com/sociedade/conte-algo-que-nao-sei/peter-pal-pelbart-nossa-sociedade-esta-esgotada-de-tudo-21231724. Acesso em: 10 jun. 2017.

\section{Dados das autoras:}

Rose de Melo Rocha - rlmrocha@uol.com.br

Professora titular do PPGCom da Escola Superior de Propaganda e Marketing - SP. Pós-Doutorado em Ciências Sociais/Antropologia pela Pontifícia Universidade Católica de São Paulo - PUCSP. 
Marina Caminha - ninacaminha@gmail.com

Pós-Doutoranda do PPGCom da Escola Superior de Propaganda e Marketing - SP. Doutora em Comunicação Social pela Universidade Federal Fluminense - UFF.

Endereço das autoras: Escola Superior de Propaganda e Marketing, Programa de Pós-Graduação em Comunicação e Práticas de Consumo. Campus Francisco Gracioso, Rua Dr. Álvaro Alvim, $123-4^{\circ}$ andar do Bloco C, Vila Mariana , 04.018010 - São Paulo (SP) - Brasil 